absence, on which I had proceeded a day or two after the accident, it appeared, by the report of the gentleman who had taken charge, that union did not ensue; it was opened in nine or ten days; a thin discharge issued; and eventually the severed part sloughed away, the stump healing by granulation. The fractured thumb had likewise exfoliated, and in both, the healing process went on very slowly.

In this instance, however, it is necessary to remark, that the injury - as injuries from machinery commonly are-was of more contused character; the habits of the patient not altogether regular, although a florid, healthy-looking man; and his age about fifty-four-circumstances all unfavourable to the object in view, though not so pointedly so as to prevent the experiment being made where no risk was incurred. It was singular that he had experienced nearly a similar injury, 15th December, 1838, a year before, almost to the day. On that occasion, while cleaning part of the machinery, he was struck on the left hand by the swaybeam of the engine, by which the third phalanx of the middle finger of the left hand was carried off, the ring finger so lacerated that I had to remove it at the second joint, and part of the hand so severely bruised, that portions of the tendons sloughed away. On this occasion, likewise, the restorative power had seemed unusually inert; but then the patient, on both occasions, was attenced in his own quarters, there being no sufficient hospital accommodation for his reception; and we invariably find, in the public service, that the strict control, order, and discipline of such an establishment, tend much to accelerate recovery.

This subject embraces a variety of other details, which may be pursued at a future period. No apology will be necessary for throwing together such remarks as possess a practical character, and tend to save any portion of the frame, however seemingly unimportant, of those who may unfortunately be sufferers from the casualties to which all are liable.

Royal Marine Hospital, Woolwich, March 1845.

\section{AN ACCOUN'T OF THE CHEMISTRY OF THE RED PARTICLES OF BLOOD.}

By W. Procter, Esq. M.R.C.S.E., York.

That important changes take place in the blood in the lungs is a fact which has been known sirce the discovery that it regularly passes through those organs, and from time to time numerous theories have been brought forward to account for such changes, but not one of them explains sufficiently the manner in which the chief agent in the metamorphosis is conveyed from the respiratory organs. But the rapid and extensive advancement of organic chemistry at the present time has already done much, and promises to do much more, for this branch of physiology.

The theory of respiration promulgated by Liebig is now generally known; his view is simple, and readily understood, the changes, according to him, being dependent on chemical facts which have long been known. He shows that the red particles of blood contain oxide of iron, and possess the property of combining with gases, and that on these two qualities depends the change of colour induced in the blood by respiration. Arterial blood, he says, contains iron as a peroxide. In contact with animal matter, this hydrated peroxide becomes the carbonate of protoxide of iron-the change, or deoxidation, taking place in the capillaries, and the deoxidized globules, in their return towards the heart, combine with carbonic acid, producing venous blood. Arrived at the lungs, in contact with water and oxygen, carbonate of iron is decomposed with evolution of carbonic acid, absorption of oxygen, and conversion into hydrated peroxide, which again, under the preceding conditions, becomes the carbonate of iron.

Thus, then, it is evident that the basis of Liebig's theory rests on the presence of peroxide of iron in arterial blood, and the changes produced thereon by the various reagents, to the action of which it is exposed. It has long been a disputed point amongst the best authorities in physiological chemistry, whether this substance exists in the blood as a metal or as an oxide. Fourcroy and Vauquelin supposed the colouring matter to be a solution of subphosphate of iron in albumen. This view the experiments of Berzelius completely destroyed, inasmuch as he found that salt is insoluble in serum, with or without the addition of an alkali; the opinion of Prevost and Dumas, that peroxide of iron with albumen is the source from whence the colour is derived, he also showed to be equally erroneous, because, if that were the case, dilute sulphuric or hydrochloric acid should dissolve out the metal; and though it is true that Liebig says it does so, Mulder remarks, it is from the clot, not the globules, that the solution takes place, from the albuminous elements, in all of which iron is found in a soluble condition. The most delicate tests of oxide of iron do not detect it in the blood; Rose endeavours to account for this on the presumption of a peeuliarity of combination, which he does, by showing that the oxide, in combination with gelatine and other organic substances, behaves in a similar manner; yet this is insufficient, for dilute acids still dissolve the metal from such artificial mixtures, while in blood they do not. Berzelius is inclined to consider that iron exists in the blood in a metallic condition as a quinary compound with nitrogen, carbon, hydrogen, and oxygen, and that the three primary compounds of the blood-viz., tibrin, colouring matter, and albumen, are merely modifications of one and the same substance; that the colouring matter, for example, may owe its peculiarity to iron.

MIulder is amongst the most recent experimentalists on the subject. He has shown, as did Englehart, that chlorine removes the iron, as a chloride of that metal, when passed through a solution of the colouring matter of blood, with formation of chlorous acid, precipitated in combination with hæmatosine, in white flakes. In this experiment the red colour disappears, but it is not to be from hence inferred that this decolorization is due to the removal of the metal. In proof that it is not so, if some dried coagulum of blood is macerated with strong sulphuric acid for some days, hydrogen is evolved, as during its action on metallic iron, with the formation of sulphate of iron, which may be separated by washing and filtration; the protein is also removed with sulphuric acid, and pure colouring matter, or hæmatosine, free from iron, is left, under these circumstances retaining its characteristic bue.

In this experiment the results are certainly somewhat complicated, on account of the interference of the various protein compounds existing in the coagulum submitted to the action of the acid; it would, consequently, be much more satisfactory to submit to experiment simply the pure red particles, which may be managed by the addition of a substance capable of preventing: the coagulation of fibrin, as thereby the globules are not enclosed in a clot. Nitrate of potassa dissolves the fibrin of venous blood; if blond, as it escapes from a vein, is allowed to fall into a solution of this salt, the red corpuscles subside, and may, by filtration and washing, be cleansed from adhering serum. When these corpuscles, thus prepared, are dried, and mixed with sulphuric acid, bydrogen is evolved, as before; sulphate of iron is in solution, ard insoluble red colouring matter, devoid of iron, is left, constituted $\mathrm{C}_{44} \mathrm{H}_{22} \mathrm{~N}_{3} \mathrm{O}_{6}$. On boiling this with alcohol, the spirit is coloured intensely red, but no iron can be detected in the spirituous solution.

As neither hydrochloric nor dilute sulphuric acid will, by long digestion, remove the iron from the blood, it is exceedingly improbable, if these agents fail in producing that oxidation, which they must do before effecting solution, that such a process shall go on in the lungs.

Mulder brings forward a stronger and more direct argument in favour of the view he upholds. In order more clearly to show this, let the equivalent of the colouring matter be doubled, which would stand thus-

$$
\mathrm{C}_{8 \mathrm{~s}} \mathrm{H}_{44} \mathrm{~N}_{6} \mathrm{O}_{12} \mathrm{Fe}_{2} \text {. }
$$

Now, assuming the metallic constituent removed by sulphuric acid to be $\mathrm{Te}_{2} \mathrm{O}_{3}$, the equation would be

$$
\begin{aligned}
& \left(\mathrm{C}_{88} \mathrm{H}_{44} \mathrm{~N}_{6} \mathrm{O}_{12} \mathrm{Fe}_{2}\right)-\mathrm{Fe}_{2} \mathrm{O}_{3}=\frac{\mathrm{C}_{89} \mathrm{H}_{44} \mathrm{~N}_{6} \mathrm{O}_{9}}{2} \\
& =\mathrm{C}_{44} \mathrm{H}_{22} \mathrm{~N}_{3} \mathrm{O}_{4 \frac{1}{2}} .
\end{aligned}
$$

But the hamatosine is $\mathrm{C}_{44} \mathrm{H}_{22} \mathrm{~N}_{3} \mathrm{O}_{6}$, which would be the result if iron simply were abstracted; but if the oxide, a resalt opposed to analysis is obtained.

Some difficulty is certainly experienced in explaining the exact mode in which metallic iron is combined with the elements of the blood-globule; still, the progress of modern chemistry has put us in possession of the knowledge of several analogous compounds. M. Le Cane holds the same opinion of the union of carbon, hydrogen, and oxygen, with phosphorus, in the fatty matter of the brain. We have also,

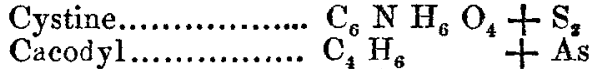

$$
\begin{aligned}
& \text { Albumen of serum... } 10 \mathrm{Pr}^{6}+\mathrm{S}_{2} \mathrm{P}_{\frac{1}{2}}
\end{aligned}
$$

In all these formula the sulphur, arsenic, and phosphorus, respectively represent iron in the globules.

If these arguments and experiments are considered sufficient to disprove the opinion that iron exists as a peroxide in the blood, some other efficient canse must be sought to explain the phenomena which are referred to its agency. The colour of arterial and venous blood is apparently unconnected with the metallic ingredient, whatever may be its chemical condition in that fluid, a detailed experiment having shown that it may be removed by sulphuric acid without affecting the colouring ingredient.

The corpuscles of the blood appear improperly to be called globules, not having, in their ordinary condition, a globular 
figure. According to Hewson, Young, Hodgkin, Lister, and Queckett, their form is that of biconcave lens-a vesicle or cell, with thickened walls, in a collapsed condition; the coverings of the cells admit of transudation, and by the addition of water to blood, endosmosis takes place, and the corpuscles acquire the form of a distended cell, with thinned coats, and become so transparent as to be with difficulty perceived. Red corpuscles thus changed may be brought back to their original form, more or less, by the action of re-agents which are capable of inducing exosmosis. The enveloping cell is composed of a peculiar protein compound, closely allied to albumen, globulin of Berzelius, which is left in combination with sulphuric acid, by the action of that acid on coagulum; whilst the internal coloured portion is hæmatosine, already sufficiently examined for our purpose.

When chlorine is passed through an albuminous fluid, chlorite of protein is formed, and precipitated in white flakes ; by the action of ammonia on this compound, a new oxide of protein, mixed with hydrochlorate of anmonia, is produced; this is tritoxide of protein, (gelatin of Bouchardat;) it is also formed when fibrin or albumen is boiled in water. It is prepared in the lungs, and is consequently found in the blood, particularly in excited states of the system, as a main ingredient of the buffy coat. By dissolving this compound in potassa, and precipitating by an acid a second oxide, the binoxide (epidermose of Bouchardat, is produced; this oxide is insoluble in water, while the former is soluble. It is probable that both these oxides are formed from the fibrin as often as the blood passes through the lungs; this is demonstrated by an experiment of Scherer: he found, by exposure of moist fibrin to oxygen, that the gas was absorbed, and carbonic acid given out, but that more of the former disappeared than was accounted for in the evolution of the latter; the loss he found to be expended in the formation of an oxycompound of protein; for the fibrin, after this exposure, on being boiled in water, left binoxide of protein undissolved, while the tritoxide was found in solution. Valentin and Brunner show that hourly $690575 \mathrm{grs}$. of oxygen are absorbed, which are not employed in forming the carbonic acid of the expired air.

Mulder avails himself of most of these facts, (many of them his own discoveries, in explaining the changes produced in the lungs by respiration. He presumes the bright red arterial blood corpuscles to be biconcave lenses, and therefore in a good condition to reflect a great amount of light; this concave form is in several ways materially influenced by the formation of oxyprotein taking place in the lungs; the contraction which will necessarily follow the formation of this "buffy" membrane, while the investing membrane being thus (as Emmert and Mayer have remarked) denser, whiter, and thicker, and consequently more opaque, will put them in a state more favourable to refiection, and necessarily heighten the colour. On reaching the systemic capillaries, the layer of oxidized protein is removed and decomposed, the protein being employed to repair the various structures, while as to the oxygen, we may adopt Liebig's opinion that it "serves to produce change of matter, and determines the separation of living parts, and their conversion into lifeless compounds, as well as the formation of the secretions and excretions." Deprived in this manner of their envelopes, the arterial become venous corpuscles, the light passes more readily through their coats, and is materially altered from the change they have undergone from the double concave to the double convex form.

Thus, then, the action of air on oxygen, or venous blood, is imputed to the absorption of the gas, not by the colouring matter, but by the protein, which is in consequence oxidized. Any agent which affects the form of the globules, and as a necessary result at the same time, their reflecting power, in a corresponding degree alters their tint; for example, saline solutions produce exosmosis in venous blood. A consequenee of this emptying is a collapsed condition, or concave form ; and the arterial hue, for reasons previously stated, is assumed; while, on the other hand, washing this blood with water, or passing through it many gases, or treating it with dilute acids, induce endosmosis, and with this alteration of physical character is produced the venous colour. Doubtless the action of carbonic acid and dilute acids may be referred to the solution of oxy-protein; an alkaline fluid, in destroying the red colour, operates in a similar manner.

Scherer is inclined to hold much the same opinion as Mulder, that the difference of colour between arterial and venous blood depends rather on physical than chemical causes, and by his experiments teuds to confirm similar views of Henle and Nasse. A quantity of fresh and bright-red blood was mixed with water; it became dark, in fact venous; and with the change of colour consequent on this dilution, the globules were found to have undergone a material physical alteration; they had lost their concave form, and had become spherical from the absorption of water by their coats. Neutral salts added to blood thus darkened changes the form and colour of the corpuscles. The microscope shows that while carbonic acid causes the corpuscles to become spherical, oxygen reduces them to a hollowed form; in this case, doubtless, the mechanical action of the substance as a gas being interfered with by the chemical property it possesses in the formation of oxy-protein. If, through the mixture of blood and water previously spoken of, oxygen is transmitted, the dark colour still remains, in all probability on account of the absence of the necessary conditions for the formation of the firm covering but if to it white particles, capable of reflecting light, as oil, milk, finely-powdered chalk, \&c., are added, then the arterial hue is assumed.

The conclusions that Scherer draws from these and other experiments are, that as the addition of distilled water cannot deoxidate the colouring matter, while neutral salts cannot add oxygen to it, and the actual addition of that gas does not produce a red colour in the blood, the change produced in the colour cannot be a chemical one. If the act of respiration in the living body, and addition of neutral salts out of it, produce the same change in the colour of the hematosine, it is possible that they both exert the same physical action as the envelopes of the blood corpuscles.

Thus, then, the opinions of both Mulder and Scherer are essentially identical, and account, in a satisfactory manner, for the phenomena of respiration; both agree in referring the whole to the different refiaction and reflection of light produced by the several forms of the corpuscles assumed under certain conditions; Mulder considering that the change of form affords a sufficient explanation; Scherer, from his experiments, though he does not appear to deny the important part that form has to do with the change of colour, seems to think that the red tint depends additionally on the presence of white reflecting particles in the blood-in fact, chyle globules.

York, March 4th, 1845.

\section{ON THE I.AW OF ASSOCIATION BETWEEN} SENTIENT AND MOTOR NERVES.

By I. Pidouck, Esq. M.D.

HOW DOES IIGHT IMPINGING ON THE RETINA EXCITE CONTRACTION OF THE IRIS?

IN replying to this question, proposed by $\mathrm{Mr}$. Stephens, of Bristol, the brain will be viewed as a whole, and the nerves as simple nniform cords of intercommunication between the brain and all parts of the body. The spinal cord will be considered as a prolongation of the brain; not as made up of separate parts, but consisting of one organ, composed of cortical and medullary substance. It is not proposed to lay aside the distinction between nerves of special sense, of sensation, of respiration, and of motion, but to regard the nervous cords as uniform in their structure Their difference in function will be regarded as arising not only from the particular portion of the brain or spinal cord, from which they originate, but from the difference in the mode of termination, and the structure of the organs on which they are expanded.

The olfactory nerve, for instance, expanded on the nasal cavities, is sensible to the stimulus of odours; the optic nerve expanded into the retina is sensible to the stimulus of light; the auditory nerve expanded upon the cochlea and semicircular canals is sensible to the stimulus of sounds; the fifth pair, terminating in the teeth and cutaneous papillæ, is sensible to objects of touch; the portio dura of the seventh pair, terminating in muscular fibres, is conducive to muscular motion; and so of the third and fourth. But for any appreciable difference in the nerves themselves, it might be safely inferred, that if the olfactory, the optic, or the anditory nerve, had been distributed to the skin, they would have been nerves of common sensation, instead of being nerves of special sense; or if they had terminated in muscular structure, they would have been nerves of motion.

The fact that each of these three classes of nerves (or to adopt the fourfold division, by distinguishing the nerves of respiration from those of motion) has a separate and distinct origin, proves nothing ; for this beautiful arrangement may have been designed for some other wise and beneficent end by the Great Author of our being, who is especially characterized as the God of Order. It may be that this arrangement may merely subserve the purpose of protection, trausmission, and distribution of the nerves which infiuence the vital functions, which minister to our enjoyment and warn us of danger, and which excite muscular exertions for our defence.

Considering, therefore, that the particular property of the three classes of nerves depends, not only upon their origin, but upon their expansion or termination, the fact that muscular contraction follows the application of a stimulus may be explained as a simple 